\title{
BIOPSIQUIATRIA E BIOIDENTIDADE: POLÍTICA DA SUBJETIVIDADE CONTEMPORÂNEA
}

\author{
Anderson Luiz Barbosa Martins \\ Universidade Estadual de Campinas, Campinas, Brasil
}

\begin{abstract}
RESUMO: Tendo como ponto de partida o surgimento do Manual Diagnóstico e Estatístico de Transtornos Mentais (DSM-III) a partir da década de 1980, marco das transformações na clínica psiquiátrica, o autor procura analisar a relação entre os discursos e práticas da psiquiatria Biológica e seus efeitos no processo de produção da subjetividade. Tomando como referência a tese foucaultiana de que a medicina é uma estratégia biopolítica, procuramos mostrar o processo de gestão do corpo e medicalização da saúde como formas de controle que encarnam o biopoder na contemporaneidade.
\end{abstract}

PALAVRAS-CHAVE: Psiquiatria Biológica, Biopolítica, Medicalização, Subjetividade.

\section{BIOPSYCHIATRY AND BIOIDENTITY: POLITICS OF SUBJECTIVITY NOWADAYS}

ABSTRACT: Having as a start the emergence of the Diagnostic and Statistical Manual of Mental Disorder (DSM-III) in the 80's, mark of transformations in psychiatric clinic, the author aims to analyze the relationship between discourses and practices of the Biological Psychiatry and their effects in production and subjectivity processes. Taking as reference Foucault's theory which states that medicine is a biopolitic strategy, we intended to describe the process of body management and medicalization of health as controlling forms which represent biopower nowadays.

KEYWORDS: Biological Psychiatry, Biopolitics, Medicalization, Subjectivity.

Nossa época tem sido designada como a era dos grandes desenvolvimentos tecnológicos: informática, tecnociência, tecnobiologias, biociências, etc., que permitiram novas descobertas e aplicações no domínio da saúde do homem. Tais descobertas têm possibilitado a fabricação de uma diversidade inédita de aparelhos, serviços, publicações, roupas, cirurgia plástica, moléculas ativas, alimentos dietéticos, bodybuilding e medicamentos destinados, sobretudo, à majoração da saúde. Entretanto, o processo constituinte do corpo eficaz, saudável, belo, jovem etc., ao mesmo tempo em que redefine a doença, a feiúra e a velhice, também revela novas normas e estratégias de controle e conduta.

Nesse contexto, Birman (1999) ressalta que a psiquiatria contemporânea vem assumindo novas composiç̃̃es e modos de funcionamento heterogêneos, que têm possibilitado a produção e sustentação de identidades globalizadas. Atravessada por um novo diagrama de forças, a medicina mental, que desde o seu nascimento, no século XIX, nunca conseguiu se fundamentar com os saberes advindos da racionalidade médica, agora pôde se aproximar da medicina somática, através de um processo de remedicalização. Com isso, afirma o autor: "completa-se o sonho do saber psiquiátrico de se transformar não apenas numa ciência, mas numa especialidade médica" (p. 2).

Em Mal-Estar na Natureza, Serpa Jr. (1998) argumenta que, desde a década de 1980, começa a se impor e a assumir a hegemonia uma versão "remedicalizada" da psiquiatria, chamada "psiquiatria biológica". Segundo o autor, a remedicalização pode ser considerada uma espécie de efeito rebote diante das fortes perspectivas de "desmedicalização" (de afastamento da psiquiatria do modelo médico), representadas pelo boom do movimento psicanalítico que dominaram o campo psiquiátrico nas décadas de 50, 60 e 70 em diversos países, principalmente nos Estados Unidos.

Entretanto, Serpa Jr. (1998) afirma que situar a década de 80 como o marco cronológico de expansão da psiquiatria biológica não significa que outras formas de tratamento biológico não tenham sido empregadas antes desse período. Antes disso, o autor ressalta o desenvolvimento da psicofarmacologia, através da descoberta de novos medicamentos (antipisicóticos, antidepressivos, ansiolíticos, estabilizadores de humor e antiepléticos), em decorrência de observações clínicas e pesquisas destinadas a sintetizar substâncias capazes de modificar o estado psíquico. Ao final dos anos 60 surgiu o modelo da 
neurotransmissão cerebral catalisado pelos psicotrópicos, provocando uma reinvenção da clínica e da terapêutica.

Embora o processo de remedicalização da psiquiatria decorra em parte dos acontecimentos ocorridos em décadas anteriores, cabe ressaltar que o termo psiquiatria biológica refere-se ao campo de pesquisa desenvolvido a partir dos anos 70, cuja principal característica consiste na tentativa de descobrir o correlato biológico das desordens psiquiátricas, com o objetivo de estabelecer sua etiologia, terapia e diagnóstico. A psiquiatria biológica desenvolve-se na relação de áreas fronteiriças, onde a psiquiatria e as ciências biológicas se cruzam, tais como endocrinologia, neuroquímica e bioquímica clínica. Posteriormente ela se ramifica, constituindo um campo autônomo, desenvolvendo seus próprios jornais, teorias, práticas e provas.

Esse panorama fica evidente, a partir dos anos 50, com a criação do DSM - Manual de Diagnóstico e Estatística dos Transtornos Mentais - pela Associação Americana de Psiquiatria. Na época, a classificação das perturbações mentais era feita através da CID-06, produzida pela Organização Mundial de Saúde. Criado com o intuito de normalizar e homogeneizar a classificação psiquiátrica, sempre alvo de críticas por sua baixa confiabilidade, o DSM acabou tendo cinco versões - I, II, III, IIIR e IV. Assim, o DSM foi utilizado como uma alternativa à Classificação Internacional das Doenças (CID).

Em 1980 é publicado o DSM-III. Sua publicação representou uma ruptura radical com as classificações até então utilizadas. Segundo Russo e Venancio (2003), a ruptura teve dois lados: em primeiro lugar, rompeu com o ecletismo das classificações anteriores, propondo não apenas uma nomenclatura única, mas principalmente uma única lógica classificatória; em segundo, representou uma ruptura com a classificação psicanalítica enquanto base hegemônica de saber-poder produzida no âmbito da psiquiatria americana.

O DSM-III vai ser caracterizado como um manual descritivo e de posição ateórica, baseado em princípios de testabilidade e verificação em que cada transtorno passa a ser identificado por critérios acessíveis à observação e mensuração empírica. Seu caráter descritivo se fundamenta em uma crítica ao modo como eram feitas as classificações anteriores, cuja base seria uma pretensa etiologia dos transtornos mentais, isto é, em processos subjacentes, inferidos pelos clínicos, e não passíveis de uma observação empírica rigorosa. Sob a radical ruptura terminológica, há um movimento de distanciamento da compreensão psicológica e psicossocial das perturbações mentais, eliminando os modelos explicativos competitivos, implícitos e explícitos, contidos nas classificações precedentes, sobretudo o modelo psicanalítico.

Henning (2000) ressalta que a recusa aos modelos etiológicos como critério de classificação resultou no corte do termo neurose, o que provou acirrados embates entre psicanalistas e os membros da força-tarefa encarregada pela APA da preparação da nova versão do DSM. Apolêmica foi resolvida por meio de uma espécie de solução de compromisso, na qual o termo deixou de figurar como uma classe de transtornos, aparecendo apenas entre parênteses ao lado de algumas categorias, como um sinônimo. Exemplo: Transtornos de Ansiedade (ou Ansiedade Neurótica) e Transtorno Distímico (ou Depressão Neurótica).

Essa posição ateórica implicou adoção de uma visão fisicalista da perturbação mental. Dito de outro modo, a objetividade dos sinais e sintomas corresponde idealmente à objetividade do substrato físico. Como conseqüência, o diálogo com o paciente sobre o seu sofrimento perde importância, bem como a preocupação com seu contexto psicossocial. Desse modo, a intervenção volta-se para uma única dimensão: o campo somático. $\mathrm{O}$ ateoricismo é, de fato, a adoção da teoria biológica e/ou fisiológica das perturbações mentais.

Desse modo, o surgimento e a difusão do sistema classificatório proposto pelo DSM-III correspondem à paulatina ascensão da chamada psiquiatria biológica como vertente dominante no panorama psiquiátrico mundial. Diferentemente das duas primeiras versões do manual, que foram preparadas por pequenos comitês acusados de não serem científicos devido à incorporação de diversas tendências e modos de conceber o diagnóstico e a prática psiquiátrica, a construção do formato do DSMIII (com suas listas de sintomas definidas por critérios de inclusão/exclusão nas categorias diagnósticas) foi incentivada pelos grandes laboratórios farmacêuticos e pelas exigências da agência reguladora norte-americana, a FDA (Food and Drug Administration), que autoriza o lançamento de novos medicamentos.

A padronização dos procedimentos diagnósticos possibilitou que o DSM-III fosse disseminado pelo mundo, através dos periódicos científicos especializados, que publicam resultados de pesquisas. Com efeito, a delimitação de fronteiras entre os diferentes transtornos levou a uma superespecificação das categorias diagnósticas, resultando num aumento exponencial do número de categorias diagnósticas e principalmente na produção de novos medicamentos psiquiátricos. Dessa forma, o DSM-III se transformou rapidamente numa espécie de bíblia psiquiátrica, levando à globalização da psiquiatria norte-americana.

\section{A medicalização da saúde}

Diante desse cenário, Serpa Jr. (2000) assinala que a padronização das classificações psiquiátricas articuladas com o desenvolvimento da genética e da neurociência tem levado a uma compreensão fisicalista do ser huma- 
no. A partir dos pressupostos biológicos, as tecnologias fisicalistas têm expandido seus domínios de atuação, englobando um número cada vez maior de perturbações mentais, assim como as regularidades de comportamentos consideradas desviantes ou socialmente problemáticas, ainda que não reconhecidas uniformemente como pertencentes a uma categoria de perturbação mental codificada.

A flexibilidade de uma ferramenta diagnóstica como o DSM-IIII permite que pesquisadores oriundos de diferentes orientações teóricas e de ambientes culturais diversos cheguem a um mesmo diagnóstico. Para tanto, a configuração sintomatológica de uma categoria diagnóstica deve ser posta em correspondência com o protótipo diagnóstico de estudos clínicos controlados e observados através dos testes laboratoriais.

Nesse processo, produz-se uma descontextualização do modo de subjetivação do paciente, inscrevendo-o num universo de valores de uso em que ele não é mais senhor de si mesmo, pois ele delega cada vez mais aos médicos especialistas o conhecimento de sua doença e de seus tratamentos. Desse modo, a psiquiatria biológica tem produzido uma des-implicação do sujeito em relação ao seu sofrimento. Isto é, se o gene é responsável por tudo e se a dor é um produto comercial, uma mercadoria que a medicina mental e seus remédios universais vão eliminar, o sofrimento deixa de ser pensado como uma narrativa ligada a uma história singular.

Nesta perspectiva, Tort (2001) afirma que, na medida em que a demanda do sujeito é transformada em demanda de saber, as repostas médicas, integradas ao saber científico, podem produzir uma somatização do sintoma, e o corpo pode aí congelar. O processo fica evidente quando o corpo é trazido, exposto, submetido ao exame, ao diagnóstico, à intervenção biomédica que acaba relativizando as formas simbólicas que o sujeito encontra para dar sentido a sua existência, como também para compreender e reagir às situações que comportam sofrimentos e mecanismos de opressão. Frente a essas somatizações induzidas, o indivíduo tende a ser capturado pelo discurso de saber-poder médico, alienando-se no mundo das tecnologias médicas.

Dessa forma, um dos efeitos considerados como iatrogênicos, produzidos pelos avanços da psiquiatria, é a produção de uma nova subjetividade no espaço da clínica médica. Esse processo ocorre, segundo o autor, quando no espaço de uma vida, suas palavras, seus símbolos e seus mitos parecem ter sido deixados junto com as roupas fora da sala de exame; quando o espaço do sentido da vida deve ser ocultado, não só pela biomedicina mas pelo próprio doente, que não se reconhece mais como o mesmo sujeito. O modo de funcionamento do dispositivo psiquiátrico, com seus protocolos de cuidados, na sua maneira de abordar a doença, acaba de alguma ma- neira anulando ou diluindo a identidade de quem está doente, portanto a doença. Nesse sentido, o sintoma se solda à pessoa, e a doença toma o lugar de identidade do doente.

Portanto, o incremento de pacientes ditos somatizantes se deve à abrangência dos efeitos, não só da biomedicina e dos tratamentos e testes de medicamentos, mas inclusive dos setores determinantes da psiquiatra biológica que ofertam e ampliam suas respostas, através das satisfações do desejo, da "medicina do desejo", na expressão de Tort. Tal medicina foi alcançada graças à rigidez dos testes randomizados, cujos dispositivos de anonimato e segredo impostos (e garantidos) pela lei resultam de um esforço para desarmar os efeitos da "sugestão" e de transferência, como forma estratégica de garantir um não-sofrimento. Nas palavras do autor: "o acesso ao real do corpo implode o dizer em seu elemento principal, em proveito do observável" (p. 331).

A transformação das experiências essenciais da vida subjetiva numa série de intervenções que ameaçam a saúde do homem retira do sofrimento seu significado íntimo e pessoal e transforma a dor em um problema técnico. A submissão à regulação faz com que a população recorra sem cessar a consumos (de medicamentos, hospitais, serviços de saúde mental etc.) cuja produção é monopolizada pela instituição médica. Esses são alguns dos sintomas da iatrogênese biomédica que começam a se impor com a expansão do saber médico na sociedade ocidental.

A virada da psiquiatria rumo à analgesia se insere dentro da mudança política que se reflete em todas as instituições contemporâneas, nas quais a dor é discutida como uma forma de regulação das funções fisiológicas. A partir desse ideal de saúde, propagado pela indústria médica, qualquer sinal de dor é visto como ultrajante e, portanto, como devendo ser aniquilado; qualquer diferença em relação ao ideal é vista como um desvio, um distanciamento maior e, insuportável, da perfeição colimada, devendo ser corrigida. Nesse processo, o indivíduo se torna um consumidor devotado aos três ídolos - anestesia; supressão da angústia e gerência de suas sensações - que o fazem obter o sentimento e a fantasia de estar em boa saúde.

Os discursos e práticas de intervenção psiquiátricas no indivíduo e no seu ambiente produziram uma medicalização da saúde, graças à multiplicação ilimitada dos papéis de doente. De acordo com Foucault (1970/ 2002), em todas as sociedades há pessoas que têm comportamentos diferentes de outras, escapando às regras comumente definidas no trabalho, na família, no discurso etc., e que acabam sendo excluídas de diversas maneiras de um domínio a outro, enquanto seus traços singulares não são assimilados numa conduta conhecida. Ao atribuir-se um nome e um papel às anormalidades, 
essas pessoas se transformam em membros de uma categoria formalmente reconhecida. Entretanto, com o desenvolvimento do campo terapêutico por meio da medicalização do diagnóstico, aumentou o número dos que possuem essa categorização social, a tal ponto que se tornaram exceção as pessoas que não entram em nenhuma categoria terapêutica. Nesse processo a saúde adquiriu, paralelamente à doença, status clínico: ela se tornou ausência de sintomas clínicos. Ou seja, a boa saúde foi associada aos padrões clínicos da normalidade.

Em o "Nascimento da Medicina Social", Foucault (1999) sinaliza os efeitos de uma medicalização da vida e do espaço social, no qual os doentes tendem a perder o "direito sobre seu próprio corpo, o direito de viver, de estar doente, de se curar e morrer como quiserem" ( $p$. 96). Assim, a medicina, como um sistema de racionalização e de controle, invadiu o campo da saúde, dilatando o da doença. Ao proclamar o desejo de gerir a população, a medicina se torna uma instância normativa, um componente do biopoder. Em nome da saúde, constituiu-se uma nova moral, uma nova economia e uma nova política do corpo. Nesse sentido, Foucault (1999) afirma:

o controle da sociedade sobre os indivíduos não se opera simplesmente pela consciência ou pela ideologia, mas começa no corpo, com o corpo. Foi no biológico, no somático, no corporal que, antes de tudo, investiu a sociedade capitalista. $\mathrm{O}$ corpo é uma realidade bio-política. A medicina é uma estratégia biopolítica (p. 80).

Ampliando a análise do processo de medicalização da sociedade, a partir de uma perspectiva foucaultiana, Clarke, Fishman, Fosket, Mamo e Shim (2000) apontam para as transformações radicais que vêm ocorrendo na sociedade pós-moderna e que implicam a participação de diversas instâncias: leigos, profissionais, companhias de seguros, administrações governamentais, indústria farmacêutica, tecnologias e instrumentos diversos. De acordo com os autores, vivemos no momento uma "nova biomedicalização" que conserva do processo de medicalização, ocorrido ao longo do século XX, a característica de expansão da jurisdição médica para novos domínios, mas repousa fortemente sobre as inovações trazidas pelas novas biotecnologias. Entretanto, o modo de funcionamento da nova forma de medicalização na sociedade contemporânea se caracteriza por intervenções que buscam não mais ajustar ou normalizar o que existe, mas transformar a própria vida.

Para Paul Rabinow (2002), a nova genética é o exemplo mais significativo desse processo, devendo remodelar a sociedade e a vida com uma força muito maior do que a revolução na física, pois será implantada em todo o tecido social por práticas médicas e uma série de outros discursos. De acordo com o autor (2002), "no futuro a nova genética deixará de ser uma metáfora biológica para a sociedade moderna e se tornará uma rede de circulação de termos de identidade e lugares de restrição" (p.143). A identidade passa a ser definida em termos biológicos e não mais a partir das categorias de sexo, idade ou raça. A produção de um homem novo opera uma ruptura sistemática com todas as formas anteriores de sociabilização. Trata-se de uma nova forma de autoprodução técnica, que Rabinow chama de "biossociabilidade".

Ampliando a noção de biossociabilidade, Ortega (2003) salienta que na cultura da biossociabilidade são produzidos novos critérios de mérito e reconhecimento, novos valores com base em regras higiênicas, regimes de ocupação de tempo e criação de modelos ideais de sujeitos baseados no desempenho físico. As ações individuais passam a ser conduzidas com o objetivo de alcançar a melhor forma física, mais longevidade, prolongamento da juventude etc. Pode-se prever, também, a constituição de novas categorias sociais a partir de um vocabulário médico-fisicalista baseado em constantes biológicas, taxas de colesterol, tono muscular, desempenho físico, capacidade aeróbica que se populariza e adquire uma conotação "quase moral", fornecendo os critérios de avaliação individual. Essa tendência exprime a criação de uma nova moral da saúde, denominada de healthism ou santéisation. "Healthism é a forma que a medicalização adquire na biossociabilidade" (p. 64).

De acordo com as análises sobre a cultura da biossociabilidade, a saúde deixou de ser a vida no silêncio dos órgãos, segundo a célebre fórmula do cirurgião René Lereche. Esse deslocamento exige uma autoconsciência de ser saudável, a saúde deve ser exibida, afirmada continuamente e de forma ostentosa, constituindo um princípio fundamental de identidade subjetiva. A "saúde perfeita" tornou-se a nova utopia biopolítica de nossas sociedades. Ela é tanto meio quanto finalidade de nossas ações. Saúde para a vida. Mas também para viver para estar em boa saúde.

\section{O imperativo da saúde perfeita}

No quadro das vertiginosas transformações operadas no âmbito da nova genética a partir da decifração do código genético humano e com o desenvolvimento das ciências da vida e das biotecnologias a elas correlatas, o sociólogo Sfez (1995), especialista na análise das tecnologias de comunicação, aponta para a configuração do novo paradigma da saúde: a saúde perfeita. Segundo Sfez, "na era da comunicação todo-poderosa, a informação sobre os problemas de saúde circula, de fato, entre as diferentes culturas, tendendo a homogeneizar as práti- 
cas particulares, e o vírus da 'saúde' tende a tornar-se universal” (p. 42). Assim, na pós-modernidade, a ideologia da comunicação, suscitada por meio das tecnologias do corpo, toma a forma de uma utopia, como um deus ex machina.

De acordo com o autor, as várias tecnologias do corpo têm permitido a produção de novas utopias, como a da saúde perfeita. No horizonte desse processo, a biopsiquiatria e sua prescrição de uma saúde para todos, fundamentada nas certezas da genética molecular e da neuroquímica, toma a forma de uma grande saúde que se impõe como única e exclusiva. A corporeidade fisiológica tornou-se um padrão de medida do homem pósmoderno. Portanto, uma grande saúde, utilizando-se de uma instrumentação hipercomplexa, vem fundar novas certezas para o homem que vai nascer. Ou seja, um homem de quem uma prescrição médica retiraria não só toda doença hereditária, mas toda a predisposição a qualquer outra doença, antes mesmo de ele ter nascido.

Segundo Illich (1999), essa obsessão pela saúde perfeita vem se tornando um “fator patógeno". É pelo fato de as tecnologias biomédicas criarem a cada momento novas necessidades de cuidados que se incrementa a oferta de saúde, o que tem levado muitas pessoas a responderem com problemas, necessidades e doenças. Criando-se ilusões de necessidades, todos pedem para que o progresso coloque fim ao sofrimento. Essa situação acaba por criar novas relações com a vida, com a saúde, com o corpo.

Nos EUA, segundo Sfez (1995), é cada vez maior a discriminação genética pelas seguradoras de saúde, pois elas não aceitam cadastrar pessoas portadoras do gene de mutação do câncer ou da doença de Huntington (doença que leva à demência). Também, os empregadores têm se interessado pelos testes genéticos como forma de avaliação de seus funcionários. Alguns pedem testes para detectar instabilidade emocional, predisposição ao alcoolismo, à depressão ou distúrbios comportamentais. Segundo o Instituto Nacional de Saúde Mental, as detecções antes dos sintomas das doenças psiquiátricas logo se tornaram rotinas. Desse modo, muitos geneticistas e psiquiatras esperam que as descobertas genéticas permitam descobrir o gene da homossexualidade, da obesidade, da agressividade, da violência, da coragem, da preguiça, do mau humor, da esquizofrenia, do mal de Alzheimer, do câncer etc.

Percebe-se então que o embasamento nas leis das probabilidades e nos cálculos dos riscos de futuras contingências, através de dados estatísticos, reduz os problemas sociais às suas dimensões biológicas. Assim, todos os problemas sociais passam a ser suscetíveis de redefinições. Se antes as dificuldades escolares eram explicadas em termos de desigualdades culturais ou in- suficiência nutricional, hoje se tende, cada vez mais, a buscar suas causas nas desordens psíquicas de origem genética, separando-se assim estes aspectos do conjunto das causas, em boa parte sociais.

Segundo a matéria intitulada "Ṕ́lulas no cardápio infantil" (Marinho \& Intrator, 2004), vem aumentando a medicalização de crianças e adolescentes para tentar emagrecer a "gorda estatística" de 155 milhões de meninos e meninas obesos no mundo. Dentre as drogas utilizadas na dieta infantil para aumentar a saciedade e reduzir a absorção de gordura, a sibutramina (substância do Reductil), um anorexígeno que diminui o apetite e provoca sintomas como boca seca, insônia, alterações do humor, vem sendo administrada em jovens a partir dos 12 anos. A liberação da droga pelo FDA, órgão que administra drogas e alimentos nos Estados Unidos, foi feita depois que os estudos coordenados pelo psiquiatra Robert Berkowitz, do Weight and Eating Disorders Program, da Universidade da Pennsylvania, comprovou "a eficácia e a segurança" do medicamento. Segundo Marinho e Intrator (2004), a culpa pela obesidade infantil deve-se às causas genéticas: "ainda não há um remédio que combata o problema genético da obesidade" (p. 27).

No contexto da medicalização infantil, o Ritalin, nome comercial do metilfenidato - um estimulante estreitamente relacionado com a metanfetamina, a droga de rua que nos anos sessenta ficou conhecida nos Estados Unidos como speed - tem sido utilizado para tratar de uma síndrome conhecida como distúrbio do déficit de atenção com hiperatividade (DDAH), uma doença comumente associada às crianças que têm dificuldade em ficar quietas nas salas de aula. De acordo com Fukuyama (2003), o distúrbio do déficit de atenção foi diagnosticado pela primeira vez como doença no Manual Diagnóstico e Estatístico dos Transtornos Mentais - o DSM I, da Associação Americana de Psiquiatria, considerado a bíblia das doenças mentais oficiais. Posteriormente, nas edições subseqüentes do manual, o nome da doença foi modificado para distúrbio do déficit de atenção com hiperatividade, hiperatividade sendo acrescentada como uma característica qualificadora. Fukuyama analisa a entrada do DDA, e depois do DDAH, no DSM como uma importante estratégia política e afirma:

apesar de várias décadas de pesquisa, ninguém foi capaz de identificar uma causa para o DDA/DDAH. Trata-se de uma patologia reconhecida apenas por seus sintomas. O DSM lista vários critérios diagnósticos para a doença, como a dificuldade de concentração e o excesso de atividade em funções motoras. Os médicos fazem o que acaba sendo um diagnóstico com freqüência altamente subjetivo quando o paciente exibe o suficiente dos sintomas listados, cuja própria existência pode com freqüência não ser facilmente determinável (p. 59). 
Com a medicalização do DDAH, milhares de estudantes são hoje tratados na sociedade americana com Ritaline ou outros medicamentos, em virtude de sua dificuldade de aprendizagem ou de perturbações que provocam em salas de aula. Segundo Fukuyama, os que acreditam estar sofrendo do distúrbio ficam com frequiência aflitos em acreditar que sua incapacidade de concentração ou de ter um bom desempenho em alguma função da vida não é, como na maioria das vezes lhe foi dito, uma questão de deficiência de caráter ou de falta de vontade, mas o resultado de uma doença neurológica. Nesse sentido, escreve Fukuyama (2003): "classificar pessoas nessa situação como sofrendo de uma patologia é portanto borrar a linha entre terapia e aperfeiçoamento" (p. 61).

A biologização do sintoma da criança naturaliza suas condutas e assimila as deficiências em relação àquilo que é considerado normal a uma patologia, e não mais a seu sofrimento imerso em uma situação em que não encontra sua razão de ser. Dessa forma, a educação familiar é protegida de qualquer dúvida quanto a seu funcionamento, mantendo-se a certeza de jamais estar errada. A escuta da criança, o suporte afetivo, o acompanhamento ao seu lado, a detecção de violências familiares ou escolares deixam de se impor quando se trata de cuidar estritamente do sintoma (a criança transformada em terminal biológico), sem ter mais de interrogar as causas (o sistema de relação em que está imersa).

Testemunha desse processo, o psiquiatra francês Zarifian (1997) explica que milhares de doses de tranqüilizantes são compradas pelos franceses. Anualmente são vendidas cerca de 115 milhões de caixas de benzodiazepinas (tranqüilizantes, soníferos etc.). A Terelena, tranqüilizante dado em forma de xarope, é um dos mais prescritos por médicos pediatras. Seguem-se o Valium e um sonífero, o Nopron, cuja tarefa é acalmar as crianças. Em média, na França, a criança vai ao médico três vezes por ano. Em 15,7\% dos casos, são prescritos medicamentos psicotrópicos. Presume-se que a criança sofra de uma disfunção cerebral leve, mesmo quando os exames neurológicos nada detectam. Trata-se, então, de uma gestão do humor que não se refere mais a um estado patológico, mas que contribui para a manutenção da ordem das coisas por meio da comodidade e da eficácia. Nesse sentido, Fukuyama (2003) declara: "se o Prozac parece ser uma espécie de pílula da felicidade, o Ritalin veio para desempenhar o papel de um instrumento patente de controle social" (p. 58).

Para Fukuyama, a difusão de drogas psicotrópicas como o Ritalin e o Prozac, nos Estados Unidos, aponta para três tendências políticas poderosas que vêm se configurando com o desenvolvimento da neurofarmacologia, contribuindo, assim, para o processo de medicalização da sociedade pós-moderna. A primeira tendência é gestão farmacológica dos problemas existenciais em pesso- as comuns; a segunda tendência se deve à pressão exercida pelos poderosos interesses econômicos das indústrias farmacêuticas; a terceira é a tentativa de medicalizar tudo, expandindo a esfera terapêutica de modo a fazê-la abranger cada vez mais um número maior de pessoas. Diante dessas transformações, diz Fukuyama (2003):

\begin{abstract}
se amanhã uma companhia farmacêutica inventasse um genuíno comprimido do soma husleyano que nos fizesse felizes e mais unidos socialmente, sem nenhum efeito colateral nocivo, .... e se um trabalhista rabugento objetasse que esse soma não era terapêutico, provavelmente se poderia contar com os psiquiatras para declarar que a infelicidade é uma patologia e introduzi-la no DSM ao lado do DDAH (p. 68).
\end{abstract}

Paul Virilio (1996) assinala que passamos hoje do super-homem ao homem superexcitado. Após a colonização geográfica do corpo territorial e da espessura geológica de nosso planeta, o recente desenvolvimento das neurociências e das biotecnologias chega hoje à progressiva colonização do corpo humano, ou seja, uma "endocolonização". Estamos agora na época dos componentes íntimos, com a criação de produtos que possam estimular as funções nervosas, a vitalidade da memória ou da imaginação, promovendo uma reestruturação das sensações através das novas tecnologias biomédicas. Virilio assinala a ênfase voltada para os nervos: um território privilegiado do estresse e de outros distúrbios típicos da contemporaneidade, como a depressão, a anorexia, a síndrome do pânico e os comportamentos compulsivos e obsessivos. Diante das novas formas de sofrimento, o sistema nervoso passa a ser o alvo fundamental dos psicofármacos e outras tecnologias da alma que se propõem a estimular e tranqüilizar os nervos superexcitados.

\section{A produção de bioidentidades}

De acordo com as análises do antropólogo Le Breton (1999), a convergência dos discursos científicos, biomédicos e informáticos tornou o corpo um acessório, um objeto imperfeito, um rascunho a ser corrigido, retificado, redefinido pelas cirurgias plásticas, pelos medicamentos, pelos regimes - ou seja, uma matéria a ser redefinida, a ser submetida ao design do momento que a indústria desenvolve para que o indivíduo adira a uma identidade efêmera. Nessa utopia técnica de purificação do homem, ressalta o autor, os discursos, graças ao progresso científico, cantam a eliminação do corpo. Se o corpo nos anos 60 encarnava a verdade do sujeito, seu ser no mundo, hoje ele não passa de um artifício submetido a uma modelação bioquímica. Trata-se de modelar o corpo que se tem, pois se acredita que, mudando o corpo, muda-se a vida 
Nesse contexto, destaca-se a transição histórica das formações sociais que constituem o que Deleuze (1992) formulou como sendo a passagem da sociedade disciplinar para a sociedade de controle. De acordo com o autor, a sociedade de controle opera por uma intensificação dos mecanismos de monitoramento disciplinares, que se estendem de forma mais difusa, flexível, móvel e imanente sobre os corpos e mentes da população, prescindindo das mediações institucionais antes necessárias, e que de qualquer forma entraram progressivamente em colapso. No novo regime de controle, de espaço liso e aberto, as novas formas de poder-saber são exercidas através de sistemas de comunicação, redes de informação, atividades de enquadramento que organizam, cada vez mais, as maneiras de sentir, amar, desejar, criar, perceber, imaginar, sonhar, mas também de vestir-se, se embelezar, habitar, fruir etc., num processo que é interiorizado e reativado pelos próprios sujeitos, o qual Hardt e Negri (2004) chamam de um estado de alienação autônoma.

No processo geral de decomposição das instituições disciplinares, em que vemos desaparecer a distinção entre a vida privada e vida pública, e mesmo entre a vida subjetiva e o simples viver, Ehrenberg (1998) assinala que, em nossa era, o homem reduzido aos seus próprios referenciais se vê impelido a agir por sua própria conta, sem que o socius lhe proporcione os referenciais subjetivos para fazê-lo. Por conseguinte, Ehrenberg postula que, com o aumento das cobranças feitas a cada indivíduo, emerge uma série de patologias relacionadas ao receio de não dar conta de escolher, de não conseguir atuar de modo livre, respondendo a todas as consequientes responsabilidades. $\mathrm{O}$ indivíduo, não tendo confiança em seus próprios recursos para se oferecer à situação, procura uma solução imediata e previsível em seus efeitos para produzir o estado moral desejado que seja adequado à realidade social.

Neste mesmo sentido, Le Breton (1999) afirma que as tecnologias não se contentam mais em cercar o corpo, protegê-lo do exterior. Elas se insinuam no interior do homem cansado de si para aliviá-lo do esforço de amansar o fato de viver. Diante do imperativo de agir a qualquer preço, aliado a uma precariedade dos elos sociais, o homem, fatigado e inseguro, entrega-se à onipotência imaginária ou real da substância consumida para provocar o estado desejado do mundo que o cerca. Logo, os medicamentos psicotrópicos acabam funcionando como auxiliares técnicos da existência, modulando o ângulo de abordagem do cotidiano, estabelecendo uma fantasia de domínio de si diante da turbulência do mundo contemporâneo. Nessas circunstâncias, diz Ortega (2003), a obediência, a adaptação e a submissão ao mundo ocupam o lugar do agir no mundo: a vontade não está a serviço da liberdade; é uma vontade ressentida, serva da ciência, da causalidade, da previsão e da necessidade, que constringe a liberdade de criação e anula a espontaneidade. Ela está submetida à lógica da fabricação, do homo faber, matriz das bioidentidades (p. 72).

Diferentemente das práticas ascéticas da Antigüidade, que visavam sempre ao outro e à cidade, expressão do amor pelo mundo, nas modernas bioasceses a vontade se define mediante critérios reducionistas, fisicistas, materiais e corporais. Os "novos estultos" não tentam mais escapar das condições de vida julgadas contestáveis ou insuficientes. Ao contrário, as pessoas nelas se arraigam, anulando, por meio de tranqüilizantes, as dificuldades a elas vinculadas ou decuplicando suas forças para, por um tempo, inscrever-se da melhor forma na manutenção de uma existência livre de riscos. Os que não conseguem alcançar e manter os ideais de saúde e perfeição corporal são vistos como expressão de uma vontade fraca.

Desse modo, a nova moral da saúde e da perfeição corporal nos faz acreditar que uma saúde pobre deriva exclusivamente de uma falha de caráter, uma personalidade defeituosa, uma fraqueza individual, uma vontade fraca. Nessa linha de pensamento, os fracos de vontade que não conseguem manter uma existência livre de riscos merecem as doenças que contraem, ao se reduzir tudo a um problema de falta de controle. Os novos estultos são alvo legítimo de repulsa moral e de ostracismo social. No interior dessa política, o sofrimento do outro não é reconhecido; é sua culpa, pois eles são donos de seu destino.

Para conduzir o comportamento propício ao estilo de vida saudável, multiplicam-se os conselhos em revistas especializadas ou não, em obras de vulgarização científica onde se estabelecem complacentemente as receitas da felicidade, do repouso e do desempenho. Nesse sentido, o discurso da psiquiatria biológica vem sendo fortemente veiculado pelos meios de comunicação, atingindo todo o tecido social numa produção massificada de subjetividades. Assim, cada vez mais as pessoas incorporam o vocabulário neurocientífico ao modo como experimentam a vida, traduzindo seus próprios sentimentos, suas motivações, seus desejos, seu caráter, seus corpos e pensamento em termos como "baixa da serotonina", "recaída da depressão", "alteração da dose do antidepressivo" etc. Para Le Breton (1999), não se trata apenas de uma medicalização do sofrimento existencial, mas também de uma fabricação psicofarmacológica de si, uma modelação química dos comportamentos e da afetividade. Essa produção bioquímica da subjetividade, que acopla o sujeito à molécula apropriada, faz do corpo o terminal de uma programação do humor, isto é, uma aliança inédita do homem e da técnica incorporada. 
Trata-se de uma forma inédita de ciborguização do indivíduo. No ensaio "Manifesto Ciborgue", Donna Haraway (2000) argumenta que o ciborgue é uma criatura que habita as fronteiras ambíguas entre o natural e o artificial, entre o humano e a máquina, entre a mente e o corpo, ou seja, ele é uma construção recente da política pós-moderna. Segundo a autora, o mundo é um mundo de redes entrelaçadas, redes que são em parte humanas, em parte máquinas; complexos híbridos de homem e máquina. Essas redes híbridas são os ciborgues e eles não se limitam a estar à nossa volta, eles nos constituem.

Para Haraway, as realidades da vida pós-moderna implicam uma relação tão íntima entre as pessoas e a tecnologia que não é mais possível dizer onde nós acabamos e onde as máquinas começam. Vale frisar que ela não está falando de algum suposto futuro ou de um lugar tecnologicamente avançado, ou isolado, mas do presente. A era ciborgue é aqui e agora, onde quer que haja uma academia de ginástica, uma prateleira de alimentos energéticos para bodybuilding, com o consumo de esteróides para aumentar a massa muscular, psicofármacos para a gestão do humor etc. Ser um ciborgue não tem a ver com quantos bits de silício temos sob nossa pele ou com quantas próteses nosso corpo contém. Tem a ver com a produção de nossos corpos artificialmente induzidos, nutridos pelos produtos das grandes indústrias de produção de alimentos, sentidos farmacologicamente excitados (percepção, imaginação, tesão), mantidos em forma sadia - ou doentia - pelas drogas farmacêuticas em interação com os procedimentos médicos.

Toxicômanos de identidade. Assim se refere a psicanalista Suely Rolnik (1997) às subjetividades contemporâneas que tendem a insistir em sua figura moderna, com sua crença na estabilidade, ignorando as forças que as constituem e as desestabilizam por todos os lados, para se organizar em torno de um referencial identitário dado a priori, mesmo que, na atualidade, não seja sempre a mesma essa representação. Portanto, os viciados em identidade, diante da sensação de ameaça de fracasso, por não conseguirem produzir o perfil-padrão requerido para gravitar em alguma órbita do mercado globalizado, tentam se anestesiar do desassossego trazido pela multiplicidade de forças da economia globalizada.

De acordo com a autora, o viciado em identidade tem horror aos vestígios das linhas do tempo em sua pele. As vertigens dos efeitos e desestabilização o ameaçam a tal ponto que, para sobreviver a seu medo, ele tenta se anestesiar: deixa vibrar em seu corpo apenas aquelas intensidades que não ponham em risco sua suposta identidade. Por esse recalcamento da vibratilidade da pele, ou seja, dos efeitos de desestabilização no corpo, ele tem a ilusão de desacelerar o processo. Entretanto, como é impossível impedir a profusão de novos territóri- os existenciais, o estado de estranhamento que tais diagramas de força provocam acaba se reinstaurando em sua subjetividade. Assim, esse homem se vê então obrigado a consumir algum tipo de droga se quiser manter a miragem de uma suposta identidade.

Várias são as estratégias que as subjetividades têm inventado na atualidade para tentar domesticar as forças provocadas pelas mudanças na contemporaneidade. Entretanto, em todas elas, tal tentativa malogra, pois não se enfrentam os vazios de sentido provocados pelas dissoluções das figuras em que se reconhecem a cada momento. Nesse sentido, segundo Rolnik (1997), neutraliza-se a tensão contínua entre figura e forças, despotencializa-se o poder disruptivo e criador da tensão, brecam-se os processos de subjetivação. A questão que se coloca para as subjetividades hoje em dia não é a defesa de identidades locais (minorias sexuais, étnicas, religiosas etc.) contra identidades globais, nem tampouco da identidade em geral contra a pulverização. O que deve ser combatido é a própria referência identitária, não em nome da pulverização (o fascínio niilista pelo caos), mas para dar lugar aos processos de singularização, de criação existencial, movidos pelo vento dos acontecimentos. Só assim poderemos investir na rica densidade de universos que povoam os modos de subjetivação, de modo a pensar o impensável e inventar novas possibilidades de vida.

Em "O Sujeito e o Poder", Foucault (1995) torna claro que as formas de resistência contra as diferentes formas de poder consistem em três tipos de lutas: a primeira, contra as formas de dominação típicas, por exemplo, das sociedades feudais; a segunda, contra as formas de exploração semelhantes às ocorridas no século XIX; a terceira são as lutas contra as formas de sujeição. Segundo o autor, as últimas são as batalhas mais recentes, pois passam por uma resistência às duas formas atuais de sujeição: uma que consiste em nos individualizar de acordo com as exigências do poder, outra que consiste em ligar cada indivíduo a uma identidade sabida, conhecida e determinada. Assim, a luta pela subjetividade se apresenta então como direito à diferença e direito à variação, à metamorfose. Luta contra um tipo de poder que envolve o governo das subjetividades. Dito nas palavras de Foucault (1995):

talvez, o objetivo hoje em dia não seja descobrir o que somos, mas recusar o que somos. Temos que imaginar e construir o que poderíamos ser para nos livrarmos deste 'duplo constrangimento' político, que é a simultânea individualização e totalização própria às estruturas do poder (p. 239).

Dessa perspectiva clínica, se a psiquiatria contemporânea toma a vida como objeto de seu exercício, isto é, se ela se faz biopoder (Foucault, 2002), interessa então pensar uma forma de resistência ao assujeitamento. Ba- 
seados na leitura de Michel Foucault, Barros e Passos (2001) propõem uma distinção entre biopoder e biopolítica que corresponda a outra distinção entre assujeitamento e subjetivação, definida então como resistência e criação. Assim, se a biopolítica é entendida como uma forma geral de dominação da vida, ela também pode significar, no seu avesso, não só semântico, mas também cultural e político, uma resistência ativa ao biopoder. Segundo os autores, essa resistência se faz biopoliticamente através de práticas de si, ou seja, a produção de um modo de existência que investe na capacidade de auto-organização ou de autopiese da vida, pois, "se o biopoder investe sobre a vida, a biopolítica é a livre expressão da potência autopoiética da vida" (Barros \& Passos, 2001, p. 96). Dessa forma, apostamos que tais descrições podem nos permitir abarcar questões do encaminhamento de nossas ações de cuidado com o sofrimento do corpo dos pacientes, através de uma prática ativa, de resistência e criação de novas possibilidades de existência e de afirmação de uma ética pela vida.

\section{Referências Bibliográficas}

Associação Psiquiátrica Americana. (1995). Manual diagnóstico e estatístico de transtornos mentais ( $4^{\mathrm{a}} \mathrm{ed}$.). Porto Alegre: Artes Médicas.

Barros, R. B. \& Passos, E. (2001). Clínica e Biopolítica na Experiência do Contemporâneo. Revista de Psicologia Clínica: PósGraduação e Pesquisa, 13(1), 89-99.

Birman, J. (1999). A psicopatologia na pós-modernidade - As alquimias no mal-estar da atualidade. Revista Latinoamericana de Psicopatologia Fundamental, 2(1), 40-46.

Clark, A., Fishman, J., Fosket, J., Mamo, L., \& Shim, J. (2000, Juin). Technosciences et nouvelle biomédicalization: racines occidentales, rhizomes mondiaux. Sciences Sociales et Santé, $18(2)$.

Deleuze, G. (1992). Post-scriptum: sobre as sociedades de controle. In G. Deleuze, Conversações (pp. 219-226). São Paulo: Editora 34

Ehrenberg, A. (1998). Lafatigue d'être soi. Paris: Odile Jacob.

Foucault, M. (1995). O sujeito e o poder. In H. Dreyfus \& P. Rabinow (Orgs.), Michel Foucault: uma trajetória filosófica para além do estruturalismo e da hermenêutica (pp. 231-249). Rio de Janeiro: Forense Universitária.

Foucault, M. (1999). O Nascimento da Medicina Social. In R. Machado (Org.), Microfísica do poder (pp. 79-98). Rio de Janeiro: Graal.

Foucault, M. (1970/2002). A loucura e a sociedade. In M. B. Motta (Org.), Ditos \& Escritos I (pp. 259-267). Rio de Janeiro: Forense Universitária.

Foucault, M. (2002). Em defesa da sociedade. São Paulo: Martins Fontes.

Fukuyama, F. (2003). Nosso futuro pós-humano: conseqüências da revolução da biotecnologia. Rio de Janeiro: Rocco.

Haraway, D. J. (2000). Manifesto ciborgue: ciência, tecnologia e feminismo-socialista no final do século XX. In T. T. Silva (Org.), Antropologia do ciborgue: as vertigens do pós-humano (pp. 37-129). Belo Horizonte: Autêntica.
Hardt, M. \& Negri, A. (2004). Império. Rio de Janeiro: Record.

Henning, M. F. (2000). Neuroquímica da vida cotidiana. Cadernos do IPUB, 18(6), 123-132.

Illich, I. (1999, Mars). L' obsession de la santé parfaite. Le Monde Diplomatique. Acesso em 28 de novembro, 2004, em http:// www.monde-diplomatique.fr/1999/03/ ILLICH/11802.html

Le Breton, D. (1999). Adeus ao corpo: Antropologia e sociedade. Campinas, SP: Papirus.

Marinho, A. \& Intrator, S. (2004). Pílulas no cardápio infantil. Revista O Globo, 1(13), 20-28.

Ortega, F. (2003). Práticas de ascese corporal e constituição de bioidentidades. Cadernos Saúde Coletiva, 11(1), 59-77.

Rabinow, P. (2002). Antropologia da razão. Rio de Janeiro: Relume Dumará.

Rolnik, S. (1997). Toxicômanos de identidade: subjetividade em tempo de globalização. In D. Lins (Org.), Cultura e Subjetividade (pp. 19-34). Campinas, SP: Papirus.

Russo, J. \& Venancio, A. T. A. (2003). Humanos demasiadamente orgânicos: um estudo comparativo de diferentes versões de um manual psiquiátrico [Resumo]. Reunião de Antropologia do Mercosul, 5, 247.

Serpa, O. D., Jr. (1998). Mal-estar na natureza. Rio de Janeiro: Te Corá Editora.

Serpa, O. D., Jr. (2000). Mente, cérebro e perturbação mental: a natureza da loucura ou a loucura na natureza? Cadernos do IPUB, 18(6), 144-157.

Sfez, L. (1995). A saúde perfeita: crítica de uma nova utopia. São Paulo: Unimarco.

Tort, M. (2001). O desejo frio: procriação artificial e crise dos referenciais simbólicos. Rio de Janeiro: Civilização Brasileira.

Virilio, P. (1995). Do super-homem ao homem superexcitado. In P. Virilio (Org.), A arte do motor (pp. 89-114). São Paulo: Estação Liberdade.

Zarifian, E. (1997). La société du bien-être. Paris: Jacob.

Anderson Luiz Barbosa Martins é psicólogo, Mestre em Saúde Pública pela ENSP/FIOCRUZ. Doutorando em Saúde Coletiva pela UNICAMP. Endereço para correspondência: Rua Antônio Galvão de Oliveira Barros, $n^{\circ} 112$ apto 11. Barão Geraldo, Cep 13084-275, Campinas-SP.

E-mail: anderluma@hotmail.com

Biopsiquiatria e Bioidentidade: política da subjetividade contemporânea

Anderson Luiz Barbosa Martins

Recebido em: 31/7/2007

Revisão: 10/01/2008

Aceite final: 16/4/2008 